\title{
From interpersonal to interorganisational trust: The role of indirect reciprocity
}

\author{
Bart S. Vanneste* \\ UCL School of Management, University College London, London, UK
}

(Received 13 November 2014; accepted 12 October 2015)

\begin{abstract}
How does interpersonal trust (i.e. between individuals) lead to interorganisational trust (i.e. between groups of individuals)? I build a bottom-up theory in which interorganisational trust arises from individuals and their dispositions, actions and observations. The theory is based on indirect reciprocity, whereby A helps B and then C helps A. Using a simulation model, I analyse (a) whether indirect reciprocity can lead to trust between two organisations even when many people are involved, when the extent of their indirect reciprocation differs, and when helping others is costly; and (b) how the presence of a boundary spanner affects this process. The main findings are that (a) indirect reciprocity can indeed create interorganisational trust under such conditions, and that, in fact, indirect may outperform direct reciprocity. Furthermore, (b) boundary spanners can decrease or increase interorganisational trust: they may decrease it by boosting their own trust at the expense of that of others, and they may increase it by enhancing indirect reciprocity for everyone through four mechanisms: contributing, discriminating, initiating and consolidating.
\end{abstract}

Keywords: interorganisational trust; interpersonal trust; indirect reciprocity; boundary spanners; simulation

\section{Introduction}

In recent decades, trust has emerged as a dominant concept for examining the structure and performance of relationships between organisations (Bradach \& Eccles, 1989; Granovetter, 1985; Gulati, 1995; Puranam \& Vanneste, 2009; Ring \& Van de Ven, 1992; Uzzi, 1997). Organisations are defined as groups of individuals (e.g. March \& Simon, 1958), yet most interorganisational trust research treats organisations as single actors. This first approximation is useful, but it is people who trust - not organisations.

Interorganisational trust is defined as the extent to which the members of a focal organisation trust the members of a partner organisation (Zaheer, McEvily, \& Perrone, 1998). Thus, the presence of interorganisational trust between two organisations, $\mathrm{A}$ and $\mathrm{B}$, implies that the individuals of both organisations trust each other. But if Alice (a member of Organisation A) trusts Bob (a member of Organisation

*Email: b.vanneste@ucl.ac.uk

Action editor: Bo Bernhard Nielsen.

(C) 2016 The Author(s). Published by Taylor \& Francis.

This is an Open Access article distributed under the terms of the Creative Commons Attribution License (http:// creativecommons.org/licenses/by/4.0/), which permits unrestricted use, distribution, and reproduction in any medium, provided the original work is properly cited. 
B), why should it follow that Amy (another member of A) trusts Brad (another member of B)? In other words, how does interpersonal trust (i.e. trust between individuals) lead to interorganisational trust (i.e. trust between groups of individuals)? The interorganisational trust literature faces the task of providing an answer because it is precisely the aggregation of trust that sets this literature apart from that on interpersonal trust (cf. Rousseau, 1985).

To account for how micro-level processes drive macro-level outcomes (Coleman, 1990), I propose an explanation based on indirect reciprocity. Reciprocity is returning an act 'in kind': good acts are rewarded and bad acts punished (Fehr \& Gächter, 2000; Gouldner, 1960). Reciprocity comes in two forms, direct and indirect (see Figure 1). Under direct reciprocity, A helps B, and then B returns a favour to A (Axelrod, 1984). Direct reciprocity underlies the canonical trust game (Berg, Dickhaut, \& McCabe, 1995; Pillutla, Malhotra, \& Murnighan, 2003). ${ }^{1}$ Under indirect reciprocity, A helps B, and then C does a favour for A (Molm, Collett, \& Schaefer, 2007; Nowak \& Sigmund, 1998). ${ }^{2}$ Findings from indirect reciprocity games indicate that we tend to give more to others the more they give to others (Milinski, Semmann, Bakker, \& Krambeck, 2001; Seinen \& Schram, 2006; Wedekind \& Milinski, 2000). Because indirect reciprocity goes beyond a dyad, it can yield insight into the link between interpersonal and interorganisational trust.

The basic argument is that indirect reciprocity helps transform interpersonal trust into interorganisational trust. Trust is the willingness to be vulnerable to the actions of another party based on an expectation that one will not be taken advantage of (Bhattacharya, Devinney, \& Pillutla, 1998; Bradach \& Eccles, 1989; Mayer, Davis, \& Schoorman, 1995; Rousseau, Sitkin, Burt, \& Camerer, 1998). In interorganisational trust, the 'other party' is not a single individual but rather the group of individuals who constitute the partner organisation; thus, a trusting act can be reciprocated by multiple people. Under indirect reciprocity, Alice's trusting act toward Bob inspires Brad to engage in a trusting act toward Alice, which in turn motivates Amy to behave similarly toward Brad. Here a trusting act between individuals (from Alice to Bob) leads to trust between groups of individuals (organisations A and B). In this simple illustration, everyone observes the actions of others and everyone reciprocates. But this may not be the case in an interorganisational relationship, especially if many people are involved and reciprocation is costly (Moldoveanu \& Baum, 2011).

Using a simulation model, I investigate (a) whether interorganisational trust can nonetheless emerge from interpersonal trust under these conditions, and (b) how the presence of boundary spanners helps or hinders this process. I build and analyse a simulation model of the relationship between two organisations in which employees

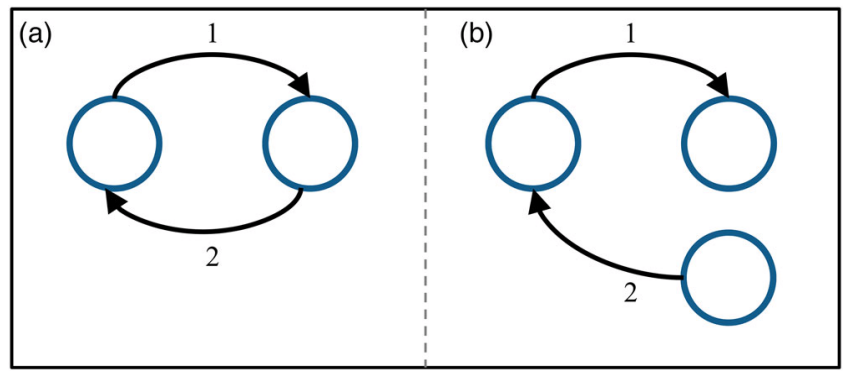

Figure 1. Direct (a) and indirect (b) reciprocity. 
of both interact with each other and differ in the extent to which they indirectly reciprocate. Information about a prior action spreads to some but not all. The model also allows for the incorporation of dedicated boundary spanners, that is, those who interact more than others.

The contributions of the paper are twofold. First, I propose a bottom-up theory in which interorganisational trust arises from individuals and their dispositions, actions and observations. The theory is based on indirect reciprocity. A positive link between interorganisational and interpersonal trust has been shown empirically (Doney \& Cannon, 1997; Zaheer et al., 1998) and is often asserted or implied (Gulati \& Sytch, 2007; Poppo, Zhou, \& Ryu, 2008; Ring \& Van de Ven, 1992). Prior explanations have invoked a 'transference process' (Doney \& Cannon, 1997; Schilke \& Cook, 2013) whereby individuals transfer perceptions of trustworthiness about known to unknown others so that both are seen as similarly trustworthy, or an 'institutionalising process' (Schilke \& Cook, 2013; Zaheer et al., 1998), whereby individuals' informal commitments are codified and over time become established and taken-for-granted organisational structures and routines. Indirect reciprocity differs from these explanations. Unlike a transference process, indirect reciprocity works even if known and unknown others are not assumed to be similarly trustworthy. As a matter of fact, in the models presented here, known and unknown others are treated differently precisely because information is available about the former but not the latter. Unlike an institutionalising process, indirect reciprocity does not rely on norms that are taken for granted. Instead, indirect reciprocity is conceptualised as an individual-level characteristic (Nowak \& Sigmund, 1998) that has been empirically shown to vary across individuals (Engelmann \& Fischbacher, 2009; Wedekind \& Milinski, 2000).

While the transference and institutionalising mechanisms are one step forward in our appreciation of the micro-macro link of interorganisational trust, they are also one step removed from an understanding of the role of interpersonal relationships. Just as an organisation is not a single actor, an interorganisational relationship is not a single relationship. Instead, it comprises the potentially numerous interpersonal relationships across organisations. Both transference and institutionalising provide explanations that abstract away from the multitude of interpersonal relationships. Such interpersonal relationships can be ignored if they are independent, but not if they are interdependent, a view strongly supported by social exchange (Cook \& Whitmeyer, 1992; Emerson, 1976) and network theory (Burt, 1992). It is precisely individual relationships, and their interdependence, that drive indirect reciprocity. To illustrate the indirect reciprocity perspective in this paper, I provide simulations as 'existence proof' (Harrison, Carroll, \& Carley, 2007) to show that indirect reciprocity independently can transform interpersonal into interorganisational trust.

To deepen this perspective, I analyse the role of boundary spanners in promoting indirect reciprocity and subsequently interorganisational trust. Boundary spanners are employees whose roles require them to interact directly with another organisation (Aldrich \& Herker, 1977; Leifer \& Huber, 1977). They are key individuals in an interorganisational relationship and act as a liaison between the focal and partner organisation (Thompson, 1967; Tushman \& Scanlan, 1981; Van de Ven, 1976). Because of this role, boundary spanners are crucial for fostering - or inhibiting - interorganisational trust (Luo, 2001; Perrone, Zaheer, \& McEvily, 2003; Seabright, Levinthal, \& Fichman, 1992; Zaheer et al., 1998). 
This brings us to the second contribution, which is to distinguish among four mechanisms through which a boundary spanner can enhance indirect reciprocity and hence interorganisational trust: contributing, discriminating, initiating and consolidating. As explained in detail later, these mechanisms are derived from crossing two main channels for indirect reciprocity - donor's propensity to trust or receiver's reputation for giving - with two possible changes - increase it or make it more reciprocating. In a nutshell, a boundary spanner can contribute to the interorganisational relationship if she is more trusting than others, discriminate in favour of those who have helped others and against those who have not to maintain the reciprocating nature of indirect reciprocity, initiate a positive chain of reciprocity by providing a trusting act and setting a positive example for others to follow, or consolidate information about others' behaviour to indirectly reciprocate appropriately.

The next section of the paper provides a theoretical background, followed by a description of the simulation model. Thereafter, I present the results, which are discussed in the final section.

\section{Theory}

\section{Interorganisational trust: who trusts whom?}

In the burgeoning literature that examines the role of trust in interorganisational relationships, trust is seen as an enabler of cooperation and an important alternative to formal governance mechanisms (Bradach \& Eccles, 1989; Gulati, 1995; Puranam \& Vanneste, 2009; Sako \& Helper, 1998; Shipilov \& Li, 2012; Uzzi, 1997). Trust is defined as

the willingness of a party to be vulnerable to the actions of another party based on the expectation that the other will perform a particular action important to the trustor, irrespective of the ability to monitor or control that other party. (Mayer et al., 1995, p. 712)

Interorganisational trust differs from interpersonal trust both in terms of the trusting party and the trusted party (Currall \& Inkpen, 2002, 2006; Fulmer \& Gelfand, 2012). For interpersonal trust, an individual trusts (or does not trust) another individual. For interorganisational trust, the employees of one organisation trust (or do not trust) the employees of another organisation (Zaheer et al., 1998). Thus, interorganisational trust originates with the trust of individual members of those organisations. This paper highlights the role of such individuals.

This paper fits in the broader literature on multi-level trust (Nielsen, 2011). A key insight from this literature is that trust at one level influences trust at another level (Rousseau, 2004). For example, trust at the societal level impacts trust at the dyad level (Reeves-Ellington, 2004), interpersonal affects team trust (Serva, Fuller, \& Mayer, 2005), and interpersonal influences interorganisational trust (Zaheer et al., 1998). I add to this literature the role of indirect reciprocity for bridging one level to the next.

\section{Interorganisational trust and indirect reciprocity}

The key mechanism in this study is indirect reciprocity. Evidence indicates that indirect reciprocity is common among humans (and even observed among fish, see Bshary \& Grutter, 2006). We tend to give more to others who themselves have given more to 
others. Much of this evidences comes from experiments, which resemble those using the trust game, with one important difference. In a trust game (e.g. Berg et al., 1995), there are two players: a donor and a receiver. The donor is given some money and must decide whether to send any of it to the receiver, whose identity remains unknown. Any money sent is augmented in that the receiver will get more than the donor sends. If the receiver does get money, she must decide how much, if any, to return to the donor. That amount is an indication of the receiver's trustworthiness because it is in her self-interest to return nothing. Trust is captured by the amount the donor sends, which represents a willingness to be vulnerable.

In the trust game, trust is based on direct reciprocity: that is, the receiver repays the donor (or not). In this paper I study interorganisational trust based on indirect reciprocity: that is, when someone other than the receiver repays the donor. Indirect reciprocity is especially relevant for interorganisational trust because the trustee is not a single individual but rather the group of members of the partner organisation. A trusting act need not be reciprocated by the receiver but could instead be returned by her colleagues. Hence, in an indirect reciprocity game, someone other than the immediate receiver repays (or does not repay) the donor.

In Wedekind and Milinski's (2000) experiment on indirect reciprocity, participants decided whether to send money to others (and any money sent would grow in transit). The donor and receiver could never meet in opposite roles, so direct reciprocity was impossible. The donor knew the receiver's history of giving or non-giving to others in earlier rounds but not the receiver's identity. Wedekind and Milinski found that the donor's decision to send money depended strongly on the receiver's history; in particular, donors indirectly reciprocated by giving more (and more frequently) to receivers with a record of giving. In this experiment and others (Milinski et al., 2001; Seinen $\&$ Schram, 2006), indirectly reciprocating a generous act is costly but could pay off in the long run if enough others reciprocate. Costly indirect reciprocity even has been observed when it cannot be beneficial over time (Engelmann \& Fischbacher, 2009; Stanca, 2009).

For two reasons, the amount of money sent in the indirect reciprocity experiments described above has varied. First, there is individual variation across donors. Some donors give more than others, regardless of who is on the other side. Following Mayer et al. (1995), I refer to this stable within-individual factor that affects someone's likelihood to trust as propensity to trust. Second, there is individual variation across receivers, which is driven by their reputation for giving. In a direct reciprocity game, only the first (propensity to trust) is relevant; the second (reputation for giving) is not because in a pure trust game such information is absent.

\section{Donor's propensity to trust}

Propensity to trust refers to the variation in donors' willingness to be vulnerable. Individuals differ in their propensity to trust, which is a stable within-individual factor (Mayer et al., 1995). It affects the extent to which the other needs to be perceived as trustworthy before someone will trust (Colquitt, Scott, \& LePine, 2007; Mayer et al., 1995; Vanneste, Puranam, \& Kretschmer, 2014). Some people only trust when they perceive the other to be highly trustworthy; some people trust even when they perceive the other only as somewhat trustworthy. Thus, two donors may trust the same party differently even when they perceive that party to have the same level of trustworthiness (Colquitt et al., 2007; Ortmann, Fitzgerald, \& Boeing, 2000). In 
the context of indirect reciprocity, propensity to trust affects a donor's willingness to be vulnerable, given the receiver's reputation for giving. Thus, in an interorganisational relationship, colleagues facing the same boundary spanner from another organisation may behave differently because of differences in their propensity to trust, even if they all have the same information about the boundary spanner.

\section{Receiver's reputation for giving}

Reputation for giving explains variations in a donor's willingness to be vulnerable across different receivers. For indirect reciprocity to function, one needs to know what others have done in the past. This information need not be perfect, but without information any kindness is unconditional. In other words, reputation matters for indirect reciprocity (Gimeno \& Woo, 1996; Nowak \& Sigmund, 2005). In the indirect reciprocity experiments cited above, information about the past was conveyed by written communication, but reputations also can be built through verbal communication or even without communication (e.g. simply by direct observation). In an interorganisational relationship, such reputations will form over time and influence how interorganisational trust develops. For instance, people are more willing to be vulnerable if their counterparts in the other organisation have been generous themselves in the past. They will be less willing to be vulnerable if their counterparts have been unhelpful.

In the simulations below, I use a setup similar to those used in experiments on indirect reciprocity. The first goal of the simulations is to analyse whether interorganisational trust can emerge from interpersonal trust through indirect reciprocity even when people differ in the extent to which they indirectly reciprocate, when helping others is costly, and when many employees are involved. The last condition makes it difficult for everyone to reliably assess all others' reputations. While the emphasis is on the emergence of interorganisational trust from individuals, not all individuals are equal. In particular, boundary spanners have been identified as key individuals who influence interorganisational trust (Gulati \& Sytch, 2008; Luo, 2001; Seabright et al., 1992). A second goal is thus to investigate how a boundary spanner helps or hinders the emergence of interorganisational trust from interpersonal trust through indirect reciprocity. By affecting who interacts with whom and who sees what, boundary spanners influence indirect reciprocity. The next section discusses the role of these boundary spanners.

The argument so far has been that interorganisational trust depends on indirect reciprocity, which in turn depends on donors' propensities to trust and receivers' reputations for giving. In the next section, I investigate how a boundary spanner can

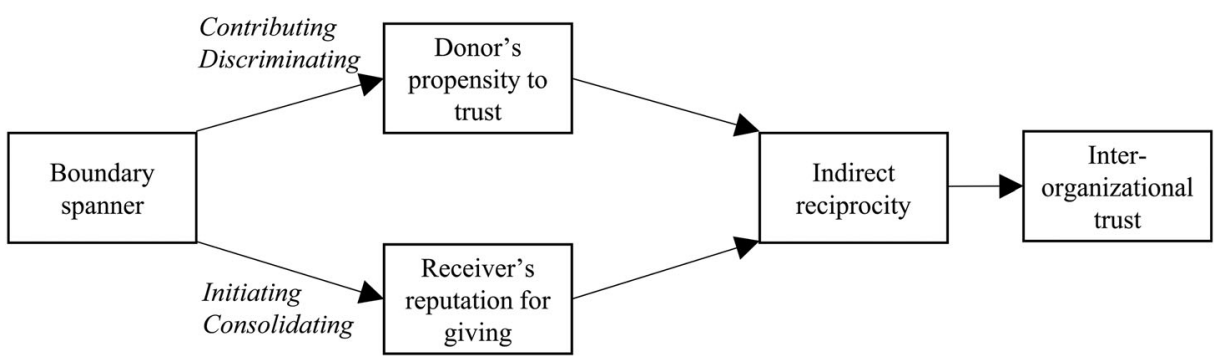

Figure 2. Conceptual model. 
influence these propensities and reputations, which in turn affects indirect reciprocity and subsequently interorganisational trust (see Figure 2).

\section{Interorganisational trust and boundary spanners}

The literature on interorganisational trust stresses the importance of boundary spanners because they can create personal attachment (Greve, Baum, Mitsuhashi, \& Rowley, 2010; Gulati \& Sytch, 2008; Luo, 2001; Seabright et al., 1992), which refers to the social bond a boundary spanner has with a member of another organisation. A stronger version of attachment is identification-based trust (Gulati \& Sytch, 2008; Lewicki \& Bunker, 1995; Shapiro, Sheppard, \& Cheraskin, 1992), whereby boundary spanners from different organisations come to identify with each other over time. They internalise others' preferences as their own, leading to higher trustworthiness and eventually higher trust. Hence, boundary spanners may develop a liking and even caring for each other.

In addition to the above, I argue that indirect reciprocity suggests four other mechanisms that may facilitate the development of interorganisational trust through boundary spanners: contributing, discriminating, initiating and consolidating. These do not depend on emotional bonds. I obtain these four different mechanisms by crossing two dimensions (see Table 1). First, in the indirect reciprocity experiments discussed earlier, the amount of money sent varies for two reasons: one is the donor's propensity to trust and the other is the receiver's reputation for giving. Thus, two channels through which a boundary spanner can affect indirect reciprocity are: donor 's propensity to trust or receiver's reputation for giving.

Second, a higher donor's propensity to trust or a higher receiver's reputation for giving is in general better for interorganisational trust. Each increases a donor's willingness to be vulnerable. But the 'higher is better' rule holds only up to a point, as indirect reciprocity only functions when an act is returned in kind. Therefore, a donor's propensity to trust should not be so high that those who do not help others are helped. Similarly, a receiver's reputation for giving should not be so high that it exaggerates how much she has helped in the past. Thus, a boundary spanner can affect the two channels - donor's propensity to trust or the receiver's reputation for giving - in two ways: by making them higher or more reciprocating than without a boundary spanner. These dimensions then suggests four different mechanisms through which a boundary spanner can facilitate indirect reciprocity.

An interorganisational relationship may contain multiple interpersonal relationships. Potentially, many employees could span the boundary that separates the two organisations. I have in mind, however, dedicated boundary spanners who are more closely involved in the interorganisational relationships and who interact more

Table 1. Mechanisms through which a boundary spanner can affect indirect reciprocity and hence interorganisational trust.

\begin{tabular}{lll}
\hline & $\begin{array}{c}\text { Donor's propensity to } \\
\text { trust }\end{array}$ & $\begin{array}{c}\text { Receiver's reputation for } \\
\text { giving }\end{array}$ \\
\hline $\begin{array}{l}\text { Higher than without a boundary spanner } \\
\begin{array}{l}\text { More reciprocating than without a } \\
\text { boundary spanner }\end{array}\end{array}$ & $\begin{array}{l}\text { Contributing } \\
\text { Discriminating }\end{array}$ & $\begin{array}{l}\text { Initiating } \\
\text { Consolidating }\end{array}$ \\
\hline
\end{tabular}




\section{B.S. Vanneste}

frequently than other employees (Gulati \& Sytch, 2008; Zaheer et al., 1998). For brevity, I refer to these simply as 'boundary spanners'. When discussing the mechanisms below, I take the perspective of a boundary spanner from the donating organisation. Hence, the donor's propensity to trust refers to that of the boundary spanner or someone from the same organisation. The receiver's reputation for giving refers to that of someone from the other organisation. This perspective is used for expositional purposes only, as both organisations will donate over the course of the relationship if indirect reciprocity takes place.

\section{Contributing (donor's propensity to trust $\times$ higher)}

Indirect reciprocity relies on people who are willing to contribute, even when doing so is risky. In an interorganisational relationship, individuals are likely to vary in their willingness to be vulnerable, that is, in their propensities to trust. By definition, individual propensity to trust is a fixed trait, but there is a choice who represents the organisation. If an employee differs in propensity to trust from others in the organisation, then the appointment of that individual as boundary spanner affects the 'donor's' propensity to trust. An especially trusting boundary spanner is particularly useful because she interacts more frequently than others with the other organisation, thereby increasing the average willingness to trust per transaction and enhancing indirect reciprocity. In this manner, a boundary spanner with a high trust propensity can contribute to the interorganisational relationship.

\section{Discriminating (donor's propensity to trust $\times$ more reciprocating)}

Indirect reciprocity is only effective if donors discriminate between those who have helped and those who have not. While a high propensity to trust is typically useful, trust that is too high risks rewarding undeserving behaviour. The logic is similar to that of a tit-for-tat strategy in a direct reciprocity game, such as a repeated prisoner's dilemma, in which cooperation is sustained precisely because that strategy discriminates between good and bad behaviour (Axelrod, 1984). Because of her involvement in numerous interactions, a boundary spanner is well placed to fulfill a discriminating role. She can discriminate in favour of those who have helped her organisation and against those who have not by trusting the former but not the latter. In a contributing role, a boundary spanner increases the baseline of trust; in a discriminating role, she increases the selectivity of trust. Thus, a discriminating role puts a limit on a contributing role.

\section{Initiating (receiver's reputation for giving $\times$ higher)}

Indirect reciprocity is path dependent: a good act will lead to more good acts, and a bad act will lead to more bad acts. In this manner, two interorganisational relationships may develop different interorganisational trust levels, even if people's trust propensities are equal across the two relationships. What makes it more likely that high instead of low trust develops? A boundary spanner can promote high trust by starting with a positive example of trusting. Through indirect reciprocity, this positive example will induce others to trust, and their trusting acts will set off further positive reciprocation. This reinforcing cycle leads to higher reputations for giving. In other words, a boundary spanner can initiate a positive string of trusting acts. Just as contributing 
works by increasing the 'donor's' propensity to trust, initiating works by increasing a receiver's reputation for giving, even if the 'donor's' propensity to trust is unaffected.

\section{Consolidating (receiver's reputation for giving $\times$ more reciprocating)}

Indirect reciprocity depends on information about prior interactions, but in an interorganisational relationship it is hard for everyone to observe everything. One remedy for this problem is to assign a boundary spanner to consolidate information about others. I consider information to be more consolidated when the same amount of it is held by fewer people. For example, instead of many employees each observing a few interactions, few employees each could observe many interactions. This process will only be helpful if the more informed employees then get the responsibility for using this information. Often, a boundary spanner is in a position both to consolidate information and then apply it by acting on behalf of the rest of the organisation. For a boundary spanner in a consolidating role, the reputation of others' giving more accurately reflects what others have done in the past. The receiver's reputation has become more reciprocating in the sense that it facilities accurate reciprocation. Similar to a discriminating role, this means that a boundary spanner can positively reciprocate those who trust and negatively reciprocate those who do not. Ultimately, indirect reciprocity depends on returning an act in kind. By consolidating information, a boundary spanner can facilitate this.

Next, I introduce the simulation model used to analyse how interpersonal trust may lead to interorganisational trust through indirect reciprocity and explain the role of boundary spanners in this process.

\section{Model}

The goal is to build a bottom-up theory where individuals' dispositions, actions and observations may or may not lead to interorganisational trust. Models, that is, simplified pictures of reality, are central to theory building in the social sciences (Lave \& March, 1993). A model can be stated in natural or formal language. The advantages of using a formal language include clarity (ideas can be communicated in a precise way), internal consistency (logical derivations can be made from a set of assumptions), and transparency about assumptions (which are made explicit) (Kreps, 1990). For these reasons, I use a formal model. A formal model's purpose dictates its complexity. One can distinguish between predicting outputs based on a set of inputs and understanding processes that transform inputs into outputs. In general, greater complexity aids predictions but hinders understanding (Axelrod, 1997). Because the current focus is primarily on understanding the mechanisms, I follow Axelrod's (1997) suggestion and build a simple model.

Based on an extensive literature review, including the works of March and Simon (1958), Stinchcombe (1965), Aldrich (1979), and Scott (1998), Puranam, Alexy, and Reitzig (2014) identify four core elements shared by different conceptualisations of an organisation: (1) a multi-agent system, (2) identifiable boundaries and (3) a system-level goal toward which (4) the constituent agent's efforts are expected to contribute. To keep the formal model simple, I restrict the organisations in the model to these four core elements. Even for a simple formal model, a closed form solution can be difficult, if not impossible, to obtain. This is the case here. Therefore, I compute solutions using computer simulations. 
The simulation is based on Nowak and Sigmund (1998), who studied the evolutionary benefits of indirect reciprocity in human populations. My approach differs in three ways. First, they modelled interactions between individuals, whereas I analyse interactions between groups of individuals (i.e. organisations). Second, they use asexual reproduction; this is unrealistic in organisations (as is large-scale sexual reproduction for that matter). Instead, I employ performance-based selection. Accommodating selection (i.e. the hiring and firing of individuals) enables me to investigate the extent to which interorganisational trust is robust to - or perhaps even enhanced by - the replacement of individuals. I also present results without selection. Third, I analyse the role of boundary spanners, who do not feature in their work. I present models with and without boundary spanners. I begin by describing the model without a boundary spanner, which is a special case of the model with a boundary spanner.

\section{Model without boundary spanner}

The basic setup of this model is as follows (see Figure 3). Each organisation has $n$ individuals. An interaction occurs between two randomly paired individuals, one from each organisation. One is randomly chosen as the donor and the other as the receiver. A donor can cooperate at a personal cost $c$, which gives a benefit $b$ to the receiver. I assume that $b>c$ so that cooperation is optimal. If a donor decides not to cooperate, then both individuals receive zero payoff. Thus, the donor must decide whether or not to cooperate.

This setup is similar to the canonical trust game in that the investment is costly for the donor and beneficial for the receiver. Unlike that game, but like an indirect reciprocity game, the receiver does not have an immediate opportunity to directly reciprocate to the donor; her subsequent transaction is more likely to be with someone else (if $n>2$ ). Even if the subsequent transaction is between the same partners, through random assignment they might have the same roles as before, making reciprocation impossible (i.e. if the receiver remains the receiver). Indirect reciprocity becomes important.

Given that indirect reciprocity is based on reputation, donors are more keen to help receivers who have helped others and less so those who have not. Each individual has an image score $s$, which reflects that person's cooperative history. After each interaction, the image score changes only for the donor. If a donor cooperates, the image score increases by 1 ; otherwise it decreases by 1 . At the beginning of the simulation, all

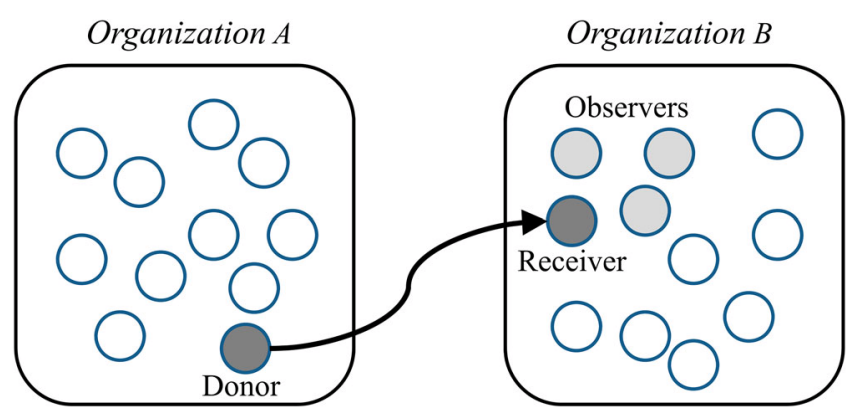

Figure 3. Simulation model. 
image scores are 0 . The image scores range from -5 to 5 (so that more weight is given to recent transactions).

A donor's decision to cooperate depends on the receiver's image score and the donor's propensity to trust, $k$, which is fixed per individual. A donor with low propensity to trust will cooperate only with a receiver who has a high image score. A donor with a high trust propensity will cooperate even with receivers who have a low image score. Specifically, a donor will cooperate if (and only if) the sum of the donor's propensity to trust and the receiver's image is non-negative. To allow for people who never trust or for those who always trust, the propensity to trust is an integer that ranges from -6 to 5 ; a donor never cooperates when $k=-6$ and always cooperates when $k$ $=5$. For any value of $k$ in between, the receiver's image score matters. The level of $k$ varies across individuals, in line with empirical findings that the degree of indirect reciprocity varies throughout the population.

Indirect reciprocity depends on knowing what others have done in the past, for example, through direct observation or hearing from others. But in an organisation, it is unlikely that everyone learns about every interaction. Therefore, let us say that each interaction is observed by $n_{\mathrm{o}}$ randomly chosen colleagues of the recipient. This includes those who see the interaction directly and those who learn about the interaction from others (e.g. from the recipient). If $n_{\mathrm{o}}<n$ then the interaction is imperfectly observed. The donor's image score is updated only for observers. This means that someone's benevolence is in the eye of the beholder. In the main models, the donor's image score is not updated for the recipient. This is unrealistic but is done for theoretical clarity. It ensures that direct reciprocity is not driving the indirect reciprocity results and allows for a comparison between direct and indirect reciprocity. I report additional models in which a donor's image score is always updated for the recipient and reach similar results. I also present results for different values of $n_{\mathrm{o}}$.

I assume that an individual's performance - the difference between the benefits received and the costs incurred - contributes positively toward his or her organisation's system-level goal. After each $t$ interaction, each organisation fires $n_{\mathrm{f}}$ employees with the lowest performance (calculated over the same interval). An equal number of outsiders are hired to replace the fired employees. If a donor has no information about a receiver, then for that donor the receiver's image score is 0 . Hence, the image score (for everyone) of a new employee is 0 , and new employees perceive everyone's image score as 0 . I provide a sensitivity analysis where I vary the value of $n_{\mathrm{f}}$, including zero (i.e. no firing).

A measure of interorganisational trust is the proportion of individuals from the partner organisation with whom the focal organisation's members are willing to be vulnerable. Because this proportion varies across members (as they may have different perceptions of others' image scores or different individual propensities to trust), I take the average per organisation. This measure accords with the definition of interorganisational trust as the extent to which the focal organisation's members trust the partner organisation's members (Zaheer et al., 1998). ${ }^{3}$

\section{Model with boundary spanner}

In this model, each organisation has one randomly chosen boundary spanner. For any interaction, a boundary spanner is more likely than others to be chosen as donor or receiver. Specifically, a boundary spanner interacts with probability $p(>1 / n)$. If a boundary spanner does not interact and is in the receiving organisation, than she 
observes with probability $q$. The model with boundary spanner is the same as the model without boundary spanner for $p=1 / n$ and $q=n_{\mathrm{o}} /[n(1-p)]{ }^{4}$ I present results for different levels of $p$ and $q$.

A boundary spanner remains in that role unless fired for low performance, in which case a newcomer becomes the boundary spanner. I also consider an alternative succession whereby an existing employee becomes the boundary spanner. As before, no receiver updates a donor's image. Therefore, any boundary spanner findings are not due to increased direct reciprocity. I also present a sensitivity analysis with direct reciprocity and find similar results. Table 2 gives an overview of the different parameters and their settings for each model.

\section{Results}

I present first the results without a boundary spanner and then those with a boundary spanner.

\section{Without boundary spanner}

Figure 4 illustrates the development of trust between two organisations from a single simulation run. The simulation settings are $n=50$ employees per organisation drawn from a population, where $k$ is uniformly distributed between -6 and 5 (inclusive). Hence, half the population has $k \geq 0$. Only people with a non-negative propensity to trust will cooperate with others whose interactions they have never observed. Alternatively, in a world without indirect reciprocity we would observe cooperation in about half of the interactions. The benefit and cost of cooperation are (respectively) $b=1$ and $c=0.1$, and each transaction is seen by $n_{\mathrm{o}}=5$ observers. After $t=750$ interactions, $n_{\mathrm{f}}=5$ employees with the lowest performance are replaced with individuals from the population. The figure shows 100 periods - that is, 100 cycles of performance evaluation.

At the beginning, trust for both organisations is around 0.50 . In other words, on average, the focal organisation's employees are willing to cooperate with $50 \%$ of the other organisation's employees. This is in line with a baseline prediction of cooperation in half the interactions (because half the population has a non-negative propensity to trust). Over time, however, owing to indirect reciprocity, interorganisational trust increases substantially, to about 0.75 .

Figure 5 compares indirect reciprocity $(\mathrm{O})$ with three benchmarks: direct reciprocity $(\Delta)$, both direct and indirect reciprocity $(+)$, and neither form of reciprocity $(\times)$. Indirect reciprocity depends on others observing the interaction between donor and recipient. For direct reciprocity, just the recipient needs to observe the interaction. To capture this distinction, the only difference between the reciprocity conditions is for whom the donor's image score is updated after each interaction. For indirect reciprocity, five employees but not the recipient update (as above). For direct reciprocity, only the recipient updates. For both direct and indirect reciprocity, five employees, including the recipient, update. For neither direct nor indirect reciprocity, no one updates.

On the horizontal axis is the population trust propensity, that is, the share of $k \geq 0$ in the population (denoted $k_{\geq 0}$ ), which varies between $10 \%$ and $90 \%$ in increments of $10 \%$. For all population conditions, individuals with negative propensity to trust are uniformly distributed between -6 and -1 inclusive, while individuals with a non-negative propensity to trust are uniformly distributed in the population between 0 and 5 inclusive. Per reciprocity/population condition, I 


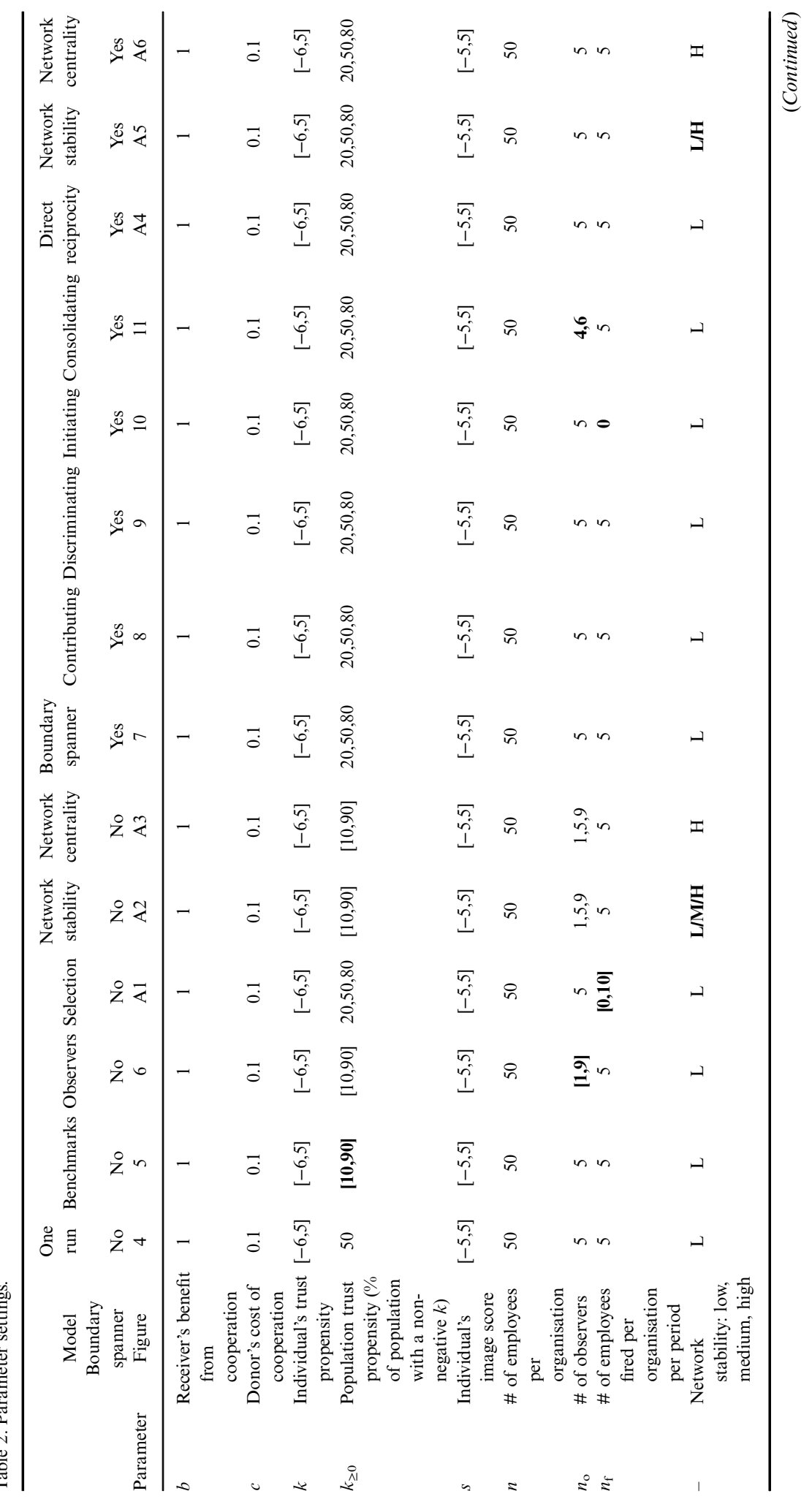




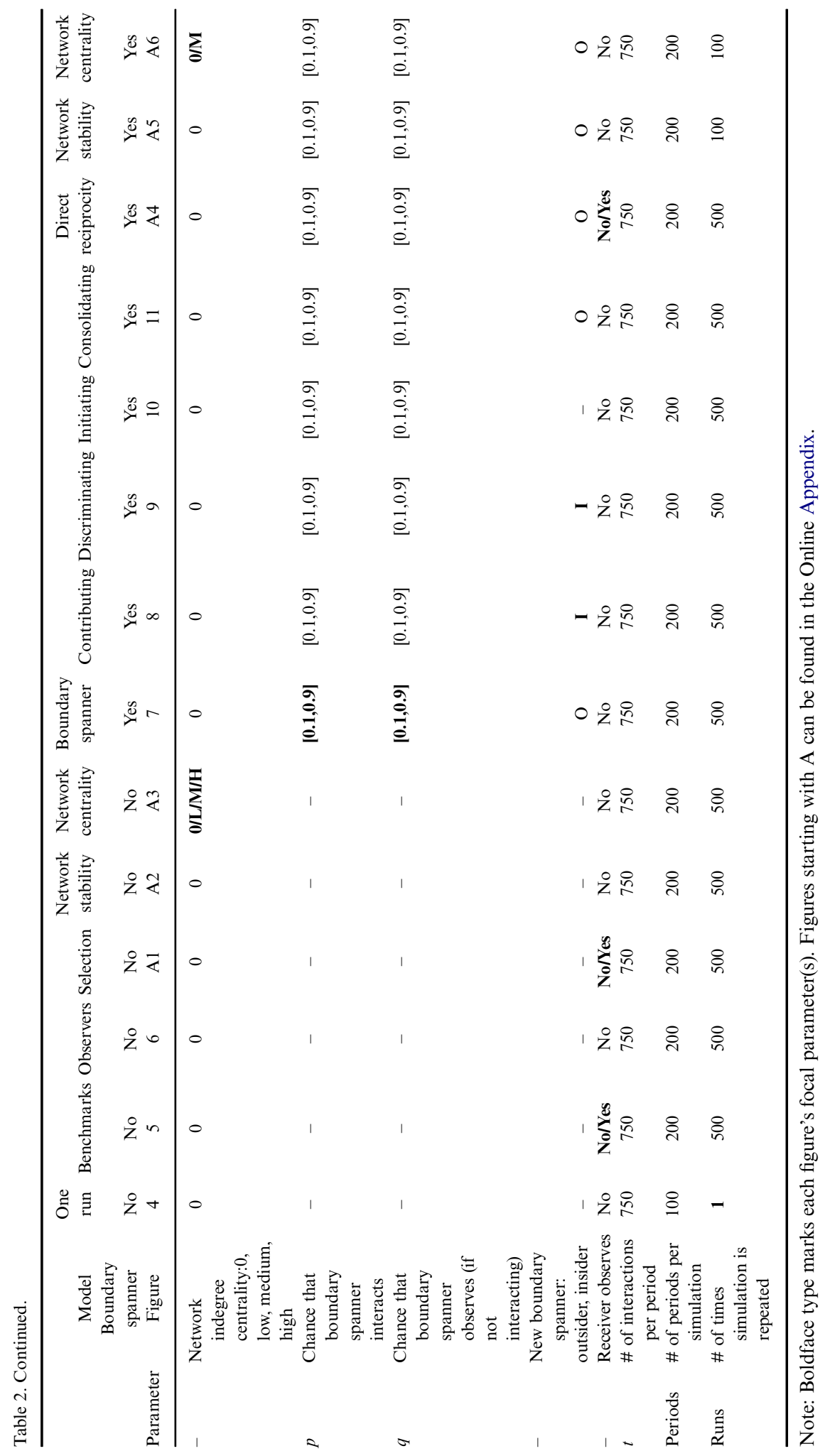




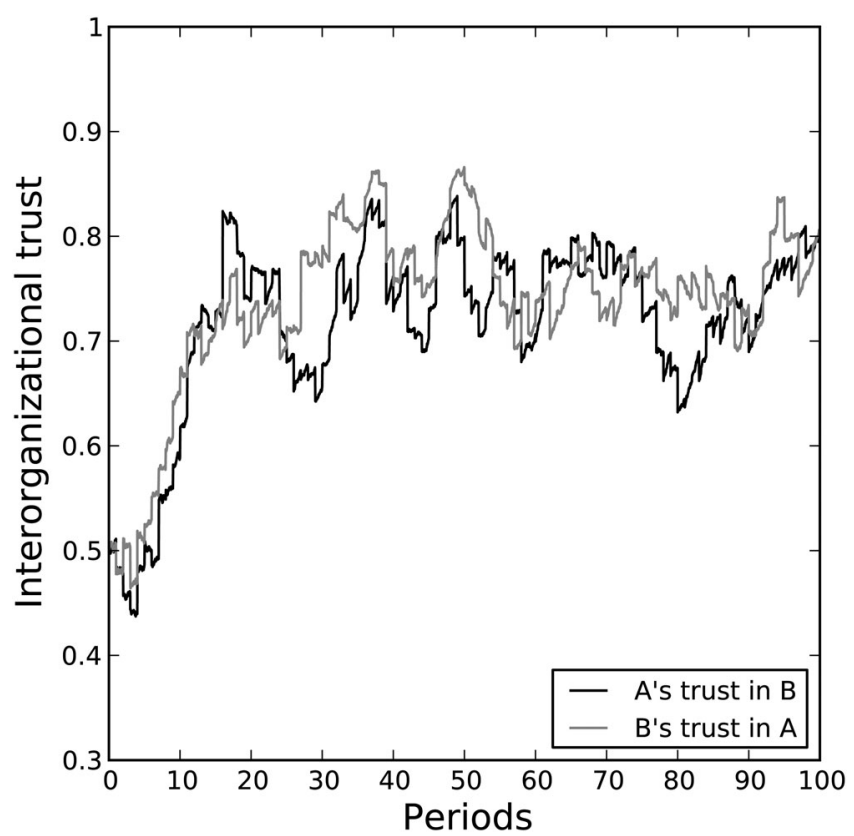

Figure 4. Development of trust between two organisations.

simulate 500 runs of 200 periods each. The remaining settings are the same as above. On the vertical axis is interorganisational trust, which is the average of the last 30 periods.

Under indirect reciprocity, for all but one condition $\left(k_{\geq 0}=10 \%\right)$, trust is greater at the end of the relationship than at the beginning. The effect is most pronounced for intermediate values of propensities to trust in the population. Hence, indirect reciprocity can increase interorganisational trust even when conditions are imperfect, as they typically are in an interorganisational relationship: not everyone indirectly reciprocates; many individuals are involved, making reputations imperfect and slow to build; and helping others is costly.

Indirect reciprocity outperforms direct reciprocity for all population conditions. Direct reciprocity in turn performs better than the condition 'neither form of reciprocity', but similar if people are reluctant to trust $\left(k_{\geq 0} \leq 30 \%\right)$. 'Neither form of reciprocity' performs the worst. Indirect reciprocity performs as well as direct and indirect reciprocity combined (except worse for $k_{\geq 0}=20 \%$ ). Thus, it matters more how many people observe (indirect reciprocity [five] vs. direct reciprocity [one]) than who observes (indirect reciprocity [five employees but not the recipient] vs. both [five employees including the recipient]). Thus, the reason that indirect performs better than direct reciprocity is that indirect reciprocity benefits from more observers.

Figure 6 illustrates that the effect of indirect reciprocity increases with the number of observers. Having more observers increases the amount of information available, making reciprocation more likely. The settings for indirect reciprocity are the same as stated previously, except that the number of observers ranges from 1 to 9 . The results for indirect reciprocity with 1 observer (see Figure 6) are similar to the results for direct reciprocity, also with 1 observer (see Figure 5). Thus, the main benefit of 


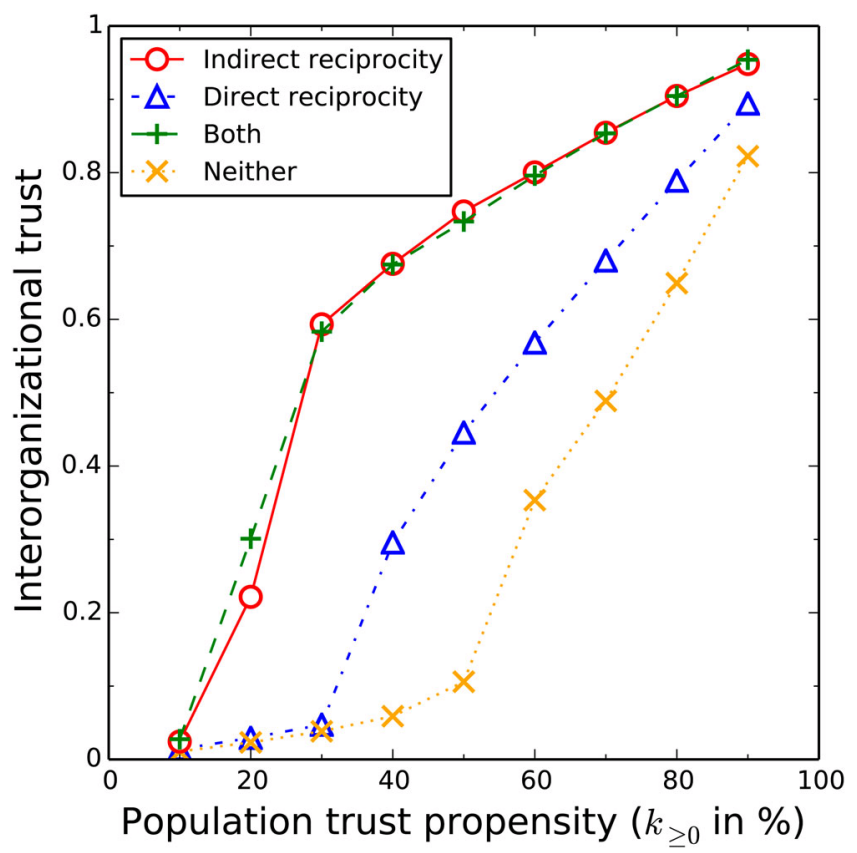

Figure 5. Comparison of indirect reciprocity with different benchmarks.

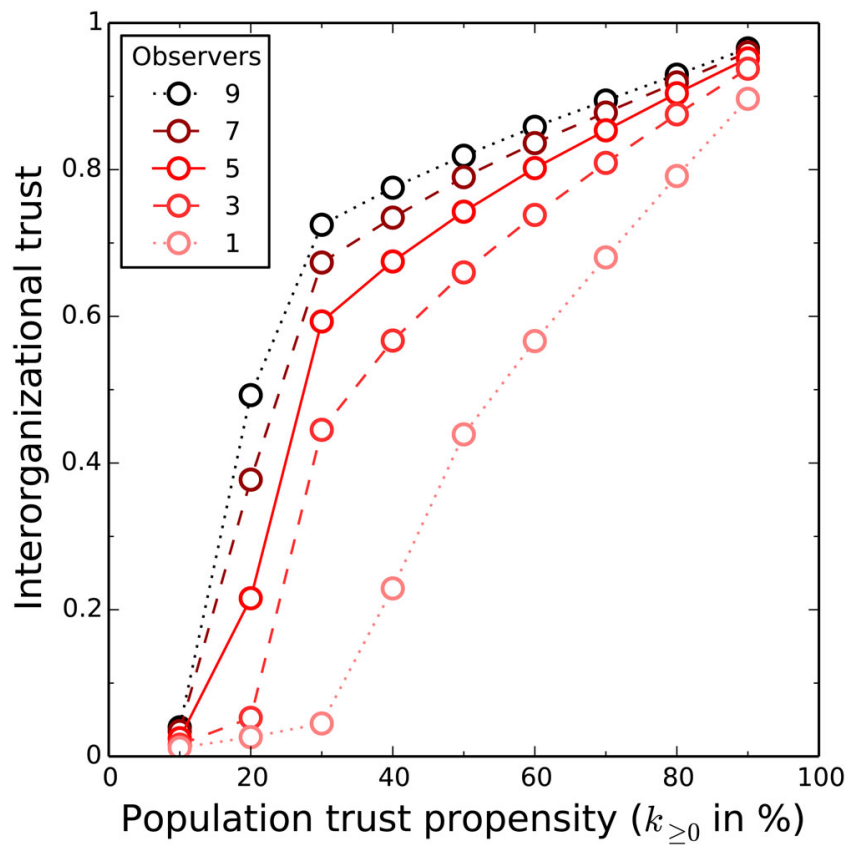

Figure 6. Interorganisational trust increases with the number of observers. 
considering indirect reciprocity in the formation of interorganisational trust is that it can incorporate the behaviours of those not directly involved in the transaction.

In short, these findings indicate that trusting acts at the individual level can lead to trust at the interorganisational level through indirect reciprocity. Because indirect reciprocity relies on reputations, the number of observers is a key factor in the spread of information.

Sensitivity analysis without boundary spanner

In the Online Appendix I present the results of three sensitivity analyses in which I vary (a) the number of people replaced, (b) the stability of the observer network and (c) the indegree centrality of the observer network. The basic results, as discussed above, continue to hold.

\section{With boundary spanner}

Figure 7(a) plots the difference in interorganisational trust with a boundary spanner relative to without a boundary spanner. The baseline is trust levels reported for indirect
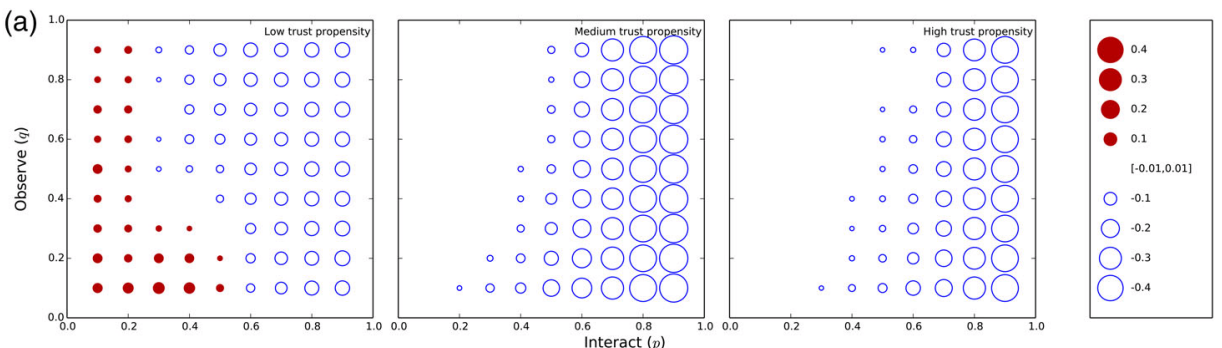

(b)
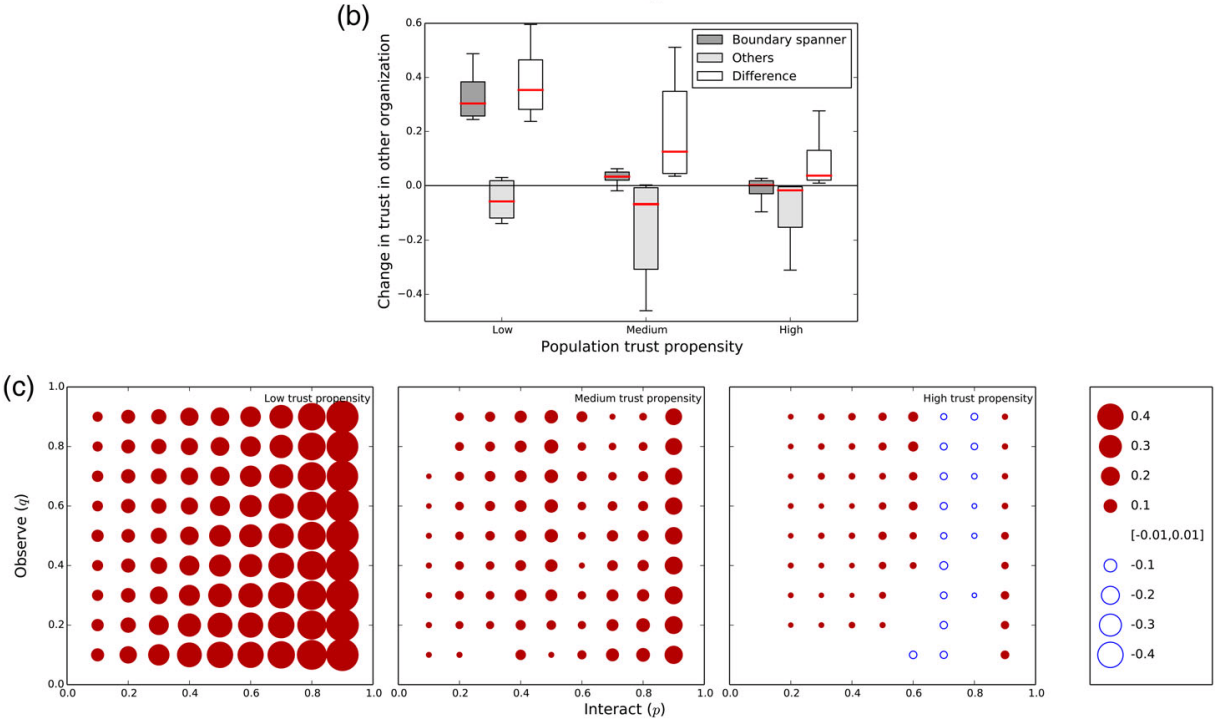

Figure 7. (a) Effect of a boundary spanner on interorganisational trust. (b) Boundary spanner's trust goes up but others' trust goes down relative to interorganisational trust without a boundary spanner. (c) A boundary spanner increases cooperation.

Note: Each box plot shows the 10, 25, 50, 75 and 90th percentiles. 
reciprocity in Figure 4. Hence, except for the boundary spanner, the settings are the same as before (e.g. a fixed level of observers $\left(n_{\mathrm{o}}=5\right)$ and of replacement $\left(n_{\mathrm{f}}=5\right)$ ). On the horizontal axis is the boundary spanner's chance of interacting, which ranges from $10 \%$ to $90 \%$ in increments of $10 \%$ (was $1 / 50$ for each employee). On the vertical axis is her chance of observing interactions in which she takes no part, which varies likewise from $10 \%$ to $90 \%$ in increments of $10 \%$ (was 5/49). I simulate results for three conditions of trust propensity in the population: low $\left(k_{\geq 0}=20 \%\right)$, medium $\left(k_{\geq 0}=50 \%\right)$ and high $\left(k_{\geq 0}=80 \%\right)$. To focus on systematic rather than random variation, absolute differences of 0.01 or less are not shown.

A boundary spanner increases interorganisational trust only when there is a low trust propensity in the population, specifically, if the boundary spanner interacts in few instances $(p \leq .2)$ or if she interacts more regularly $(.3 \leq p \leq .5)$ in combination with low chances of observing $(q \leq .3)$. The maximum increase is $0.07(p=.3, q$ $=.1$ ) from a baseline of 0.23 without a boundary spanner. However, for many other instances, especially for higher chances of interacting $(p>.5)$, a boundary spanner reduces the level of interorganisational trust.

A boundary spanner's impact on trust is asymmetric: a boundary spanner tends to trust more, everyone else less. Figure 7(b) shows for the same simulation runs that the boundary spanner's trust in the other organisation (dark grey boxes) tends to increase relative to the average without a boundary spanner. In contrast, the rest of the organisation's trust in the other organisation (light grey boxes) declines in most instances relative to the same baseline. For ease of comparison, only the aggregate results are shown. Per population trust propensity condition, each box plot shows the 10, 25, 50, 75 and 90th percentiles of the 81 parameter settings (chance of interacting between $10 \%$ and $90 \% \times$ chance of observing between $10 \%$ and $90 \%$ ). The white boxes indicate the difference between the boundary spanner's trust in the other organisation and that of others' trust in the other organisation. Thus, having boundary spanners to manage the interorganisational relationship may result in boundary spanners having high trust and everyone else having low trust.

A boundary spanner's increased involvement, however, leads to more cooperation. Figure 7(c) shows changes not in interorganisational trust but in the degree of cooperation, or the proportion of interactions in which a donor cooperates. For most settings, a boundary spanner increases cooperation, even if interorganisational trust decreases. The explanation for increased cooperation is that a boundary spanner trusts more (i.e. a higher willingness to be vulnerable) and she participates in more interactions (i.e. leading to more cooperation). For example, $p=.9, q=.2$, and low trust propensity provides the maximum increase in cooperation, 0.63 (i.e. from 0.23 to 0.86 ), while interorganisational trust drops 0.14 . Likewise, $p=.9, q$ $=.7$, and medium trust propensity provides the maximum decrease in interorganisational trust, 0.50 (i.e. from 0.74 to 0.24 ), yet cooperation rises 0.16 . In fact, interorganisational trust and cooperation do not move together. Across the different values for $p$ and $q$, their correlation is -0.77 (for low trust propensity), -0.61 (for medium trust propensity) and 0.17 (for high trust propensity). In the absence of a boundary spanner, interorganisational trust and degree of cooperation converge to each other (to the third decimal). In contrast, in the presence of a boundary spanner, there is a tradeoff between interorganisational trust and cooperation (for low and medium trust propensity).

In short, in terms of interorganisational trust (i.e. a collective willingness), a boundary spanner comes at a cost. Because the boundary spanner's increased 
frequency of interacting implies a lower frequency for the others, it is harder for other employees to earn reciprocation. It is also more challenging to reciprocate appropriately (if the frequency of observing is lower). Unless a boundary spanner compensates in other ways, interorganisational trust will go down. Next, I illustrate four such compensatory mechanisms: contributing, discriminating, consolidating and initiating.

\section{An illustration of contributing}

I consider two different rules for the choice of a boundary spanner. Previously, an underperforming boundary spanner was replaced by an outsider. Now, an outsider still enters the organisation when a boundary spanner underperforms, but instead an insider becomes a boundary spanner. Under the first assignment rule, the new boundary spanner is the best performer in the preceding round; under the second, she is a random employee. For each assignment rule I simulate as before 81 parameter settings per population trust propensity condition (chance of interacting between $10 \%$ and $90 \% \times$ chance of observing between $10 \%$ and $90 \%$ ). Figure 8 shows the aggregate results of how a boundary spanner influences interorganisational trust under the new assignment rules. Shown as the horizontal axis, the baseline is interorganisational trust without boundary spanner. Each box plot indicates the $10,25,50,75$ and 90th percentile percentiles of the 81 parameter settings. The white boxes show the difference between the two assignment rules. They illustrate that picking the best performer leads to similar or more trust than picking a random employee as boundary spanner.

This is an illustration of the contributing mechanism, whereby a boundary spanner contributes positively to the interorganisational relationship by being willing to be vulnerable. The best performer typically has a higher propensity to trust than a randomly

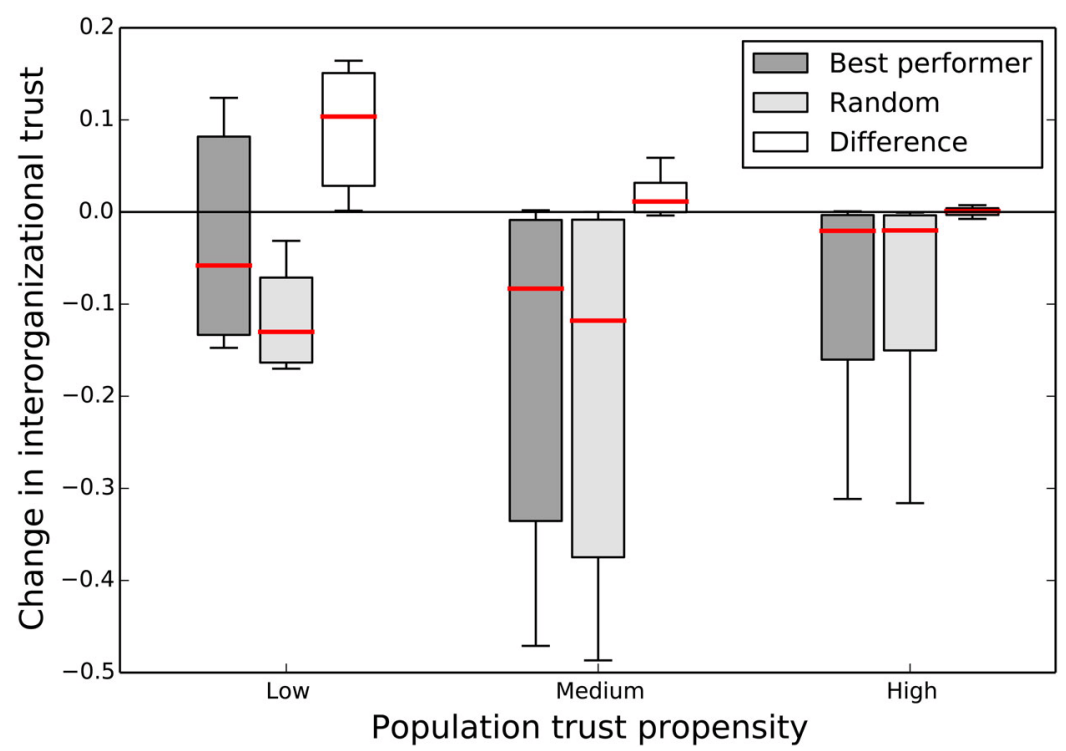

Figure 8. Contributing: a boundary spanner performs better for interorganisational trust when she was the best performer rather than randomly chosen.

Note: Each box plot shows the 10, 25, 50, 75 and 90th percentiles. 
chosen employee (because any compensation is more likely to go to those with a high propensity to trust). This is true except for high propensity to trust, at which point most employees are willing to be vulnerable and can do well in a cooperative environment. This explains why there is little difference in the effect of a boundary spanner for high trust propensity. In any case, the effect of a contributing boundary spanner would be smaller at high population trust propensities because the boundary spanner's willingness to be vulnerable would not be far from that of others.

\section{An illustration of discriminating}

A boundary spanner with a maximum propensity to trust no longer discriminates between good and bad behaviours. I compare the impact on interorganisational trust of such a boundary spanner with that of a boundary spanner who has a propensity to trust just below the maximum. In both cases, an insider is the incoming boundary spanner. The boundary spanner has $k=5$ (willing to be vulnerable to anyone) in the first case and $k=4$ (willing to be vulnerable to anyone except those with a reputation of no cooperation at all) in the second case. If no insider has the desired level of trust propensity, a random employee is chosen as boundary spanner. All other settings are as stated previously (e.g. 81 parameter settings per population trust propensity condition: chance of interacting between $10 \%$ and $90 \% \times$ chance of observing between $10 \%$ and $90 \%$ ).

Figure 9 shows that a boundary spanner can increase or decrease trust. More importantly for the discussion here, a discriminating boundary spanner is better than a non-discriminating one for interorganisational trust, as shown by the white boxes (which indicate the difference between the two conditions). This holds for all levels of population trust propensity.

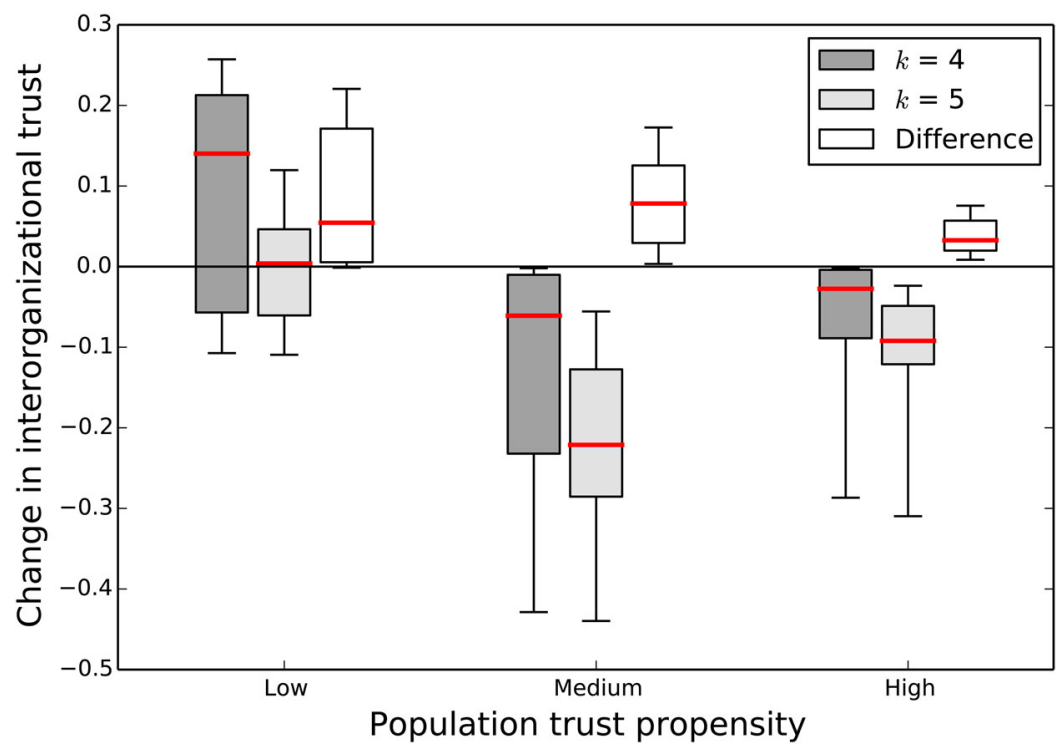

Figure 9. Discriminating: a boundary spanner performs better for interorganisational trust when she has a trust propensity just below the maximum rather than the maximum. Note: Each box plot shows the 10, 25, 50, 75 and 90th percentiles. 


\section{An illustration of initiating}

A boundary spanner can initiate a positive chain of reciprocity. To isolate this effect, I hold constant the propensity to trust within a relationship by not allowing for hiring and firing (i.e. $n_{\mathrm{f}}=0$ ). In the absence of firing, the boundary spanner remains the same throughout. I compare two alternatives. In the first, a boundary spanner always cooperates in the first period. In the other 199 periods, her decision to cooperate is as before, making cooperation dependent on her propensity to trust and on the receiver's reputation. In the second specification, a boundary spanner never cooperates in the first period; for the remaining periods, she reverts to the old decision rule. All other settings remain the same (e.g. 81 parameter settings per population trust propensity condition: chance of interacting between $10 \%$ and $90 \% \times$ chance of observing between $10 \%$ and $90 \%$ ).

Figure 10 illustrates that an initial difference has lasting consequences. A boundary spanner who cooperates in the first period does better for interorganisational trust than one who initially refuses to cooperate, even when trust is considered long after (i.e. the average from periods 171 to 200). Depending on a boundary spanner's chance of interacting, the adjusted decision rule applies only to between $0.05 \%$ and $0.45 \%$ of all interactions. Yet, the consequences remain noticeable.

\section{An illustration of consolidating}

Figure 11 shows the effect of a boundary spanner on interorganisational trust when the number of observers is four or six (was five). Each condition is compared with its own baseline (e.g. four observers with a boundary spanner vs. four observers without a boundary spanner). All other settings remain the same (e.g. 81 parameter settings per population trust propensity condition: chance of interacting between $10 \%$ and

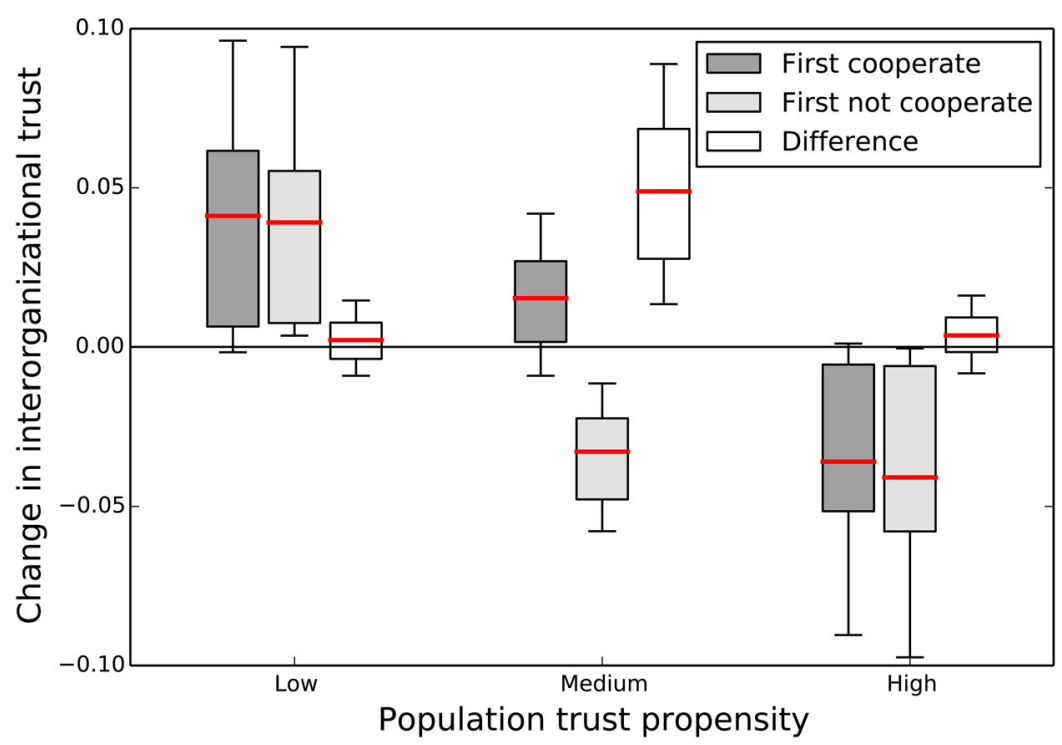

Figure 10. Initiating: A boundary spanner's initial cooperation has a long-term positive effect on interorganisational trust.

Note: Each box plot shows the 10, 25, 50, 75 and 90th percentiles. 
$90 \% \times$ chance of observing between $10 \%$ and $90 \%$ ). The effect of a boundary spanner is greater with four than six observers, as shown by the white boxes that indicate the difference between the two conditions.

The difference is in line with greater information consolidation with four than six observers. The average donor will have less information under four observers because fewer interactions will have been observed. However, as is shown mathematically in the Appendix, it is precisely when little information is available that a boundary spanner does well at consolidating it. Thus, under four relative to six observers, the average donor will have less information, but that information becomes more consolidated with a boundary spanner. Because indirect reciprocity depends on knowing what others have done, this gives a relative advantage to using a boundary spanner with four than six observers.

Put differently, whether the average donor has more information with or without a boundary spanner depends on $p$ and $q$ (i.e. the specification of what a boundary spanner does). For example, if a boundary spanner always interacts but never observes, then the average donor will know less. If a boundary spanner observes and interacts relatively frequently, then the average donor will know more than the average donor in the absence of a boundary spanner. For a given $p$ and $q$, however, as the number of observers decreases, the average donor with a boundary spanner gets an advantage relative to the average donor without a boundary spanner.

To recap, the effect of boundary spanners is not uniformly positive because interorganisational trust is a collective willingness to be vulnerable. While typically a boundary spanner's trust in the other organisation is high, others' trust may be negatively affected. A boundary spanner can facilitate indirect reciprocity and hence

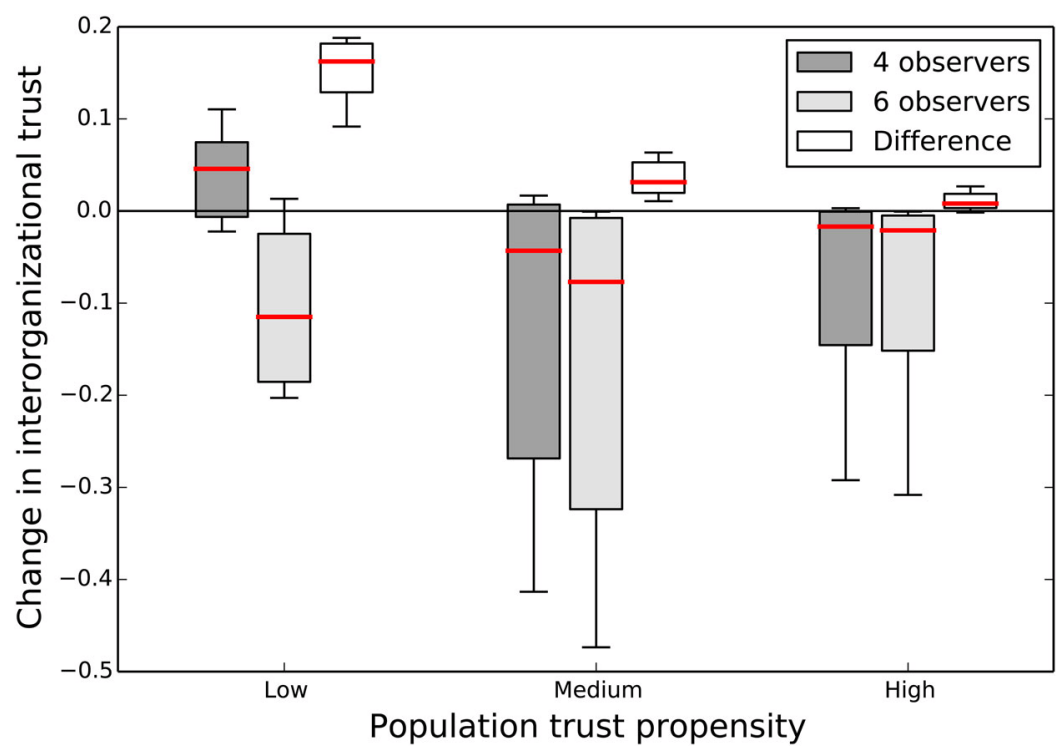

Figure 11. Consolidating: A boundary spanner does better for interorganisational trust with four rather than six observers.

Note: Each box plot shows the 10, 25, 50, 75 and 90th percentiles. 
increase interorganisational trust through one of four mechanisms: contributing, discriminating, initiating, or consolidating.

\section{Sensitivity analysis with boundary spanner}

Further sensitivity analyses can be found in the Online Appendix: (a) allowing for direct reciprocity, (b) varying the stability of the observer network and (c) varying the indegree centrality of the observer network. The results are consistent with those reported above.

\section{Discussion}

Interorganisational trust has been hailed as one of the key drivers of relationship success (Dyer \& Chu, 2003; Gulati \& Nickerson, 2008; Krishnan, Martin, \& Noorderhaven, 2006). Ultimately, such trust comes from the individuals in an interorganisational relationship. But how does trust spread from two individuals to two organisations? I propose that indirect reciprocity facilitates the emergence of interorganisational from interpersonal trust. By construction, indirect reciprocity relies on more than two individuals, which is necessary to meaningfully discuss interorganisational trust.

\section{Main findings}

The main findings are as follows. Indirect reciprocity can help establish interorganisational trust when individuals interact under conditions common to an interorganisational relationship but not necessarily conducive to trust building: many people, people differ (some easily trust and others do not), and helping others is costly. In addition, indirect reciprocity can create more interorganisational trust than direct reciprocity. Under direct reciprocity, a trusting act generates a response from no more than one person, whereas under indirect reciprocity, a trusting act can be reciprocated by many others if information spreads well. The number of observers is thus a key driver of indirect reciprocity. To ease comparison, in the models shown here the strength of reciprocation is equal for direct and indirect reciprocity. This may be a reasonable assumption to start. In a laboratory setting, Stanca (2009) found that initiating and reciprocating behaviours are similar under direct and indirect reciprocity.

The findings for boundary spanners are mixed at the organisational level: they may decrease or increase interorganisational trust. At the individual level, the findings are more clear-cut: a boundary spanner's trust in the other organisation is high relative to that of her colleagues and also high relative to the situation without a boundary spanner. This holds across all conditions, including those for which the individual boundary spanner results are not reported. So, by dominating the interorganisational relationship, there is a risk that a boundary spanner may crowd out the trust of colleagues.

Such domination might be bad for interorganisational trust but good for cooperation. A boundary spanner typically increases the level of cooperation, even if interorganisational trust declines. Again, this holds across all conditions, including where cooperation levels are not shown. Without a boundary spanner, interorganisational trust and cooperation converge completely; with a boundary spanner, they diverge. Thus, the aggregation from the individual to the organisational level can yield substantially different results. 
It is important to keep in mind that these findings come from a simulation model, not from an empirical context. These findings are used as existence proofs (Harrison et al., 2007) - for example, to show that the boundary spanner mechanisms (contributing, discriminating, initiating and consolidating) follow from indirect reciprocity. They are useful to the extent that they illuminate theoretical mechanisms.

\section{Theoretical contributions}

This study makes two theoretical contributions to the literature on interorganisational trust. First, it documents how interorganisational trust can emerge from interpersonal trust through indirect reciprocity - that is, when kind and unkind acts are returned by others. Second, the study shows how the presence of boundary spanners affects indirect reciprocity and hence the emergence of interorganisational trust.

The indirect reciprocity mechanism is distinct from prior explanations that hinge on employees perceiving both familiar and unfamiliar others in a partner organisation to be similar (Doney \& Cannon, 1997; Schilke \& Cook, 2013), or on norms and roles becoming institutionalised, after which trust becomes tied more to the organisation than to any specific individual (Schilke \& Cook, 2013; Zaheer et al., 1998). While distinct, indirect reciprocity does not invalidate these other mechanisms. In fact, they may - and probably do - coexist. Unlike these other mechanisms, however, indirect reciprocity takes into account the multitude of interpersonal relationships that make up an interorganisational relationship and their interdependence. To develop the indirect reciprocity perspective, I have analysed the specific role that boundary spanners play in it.

A boundary spanner can influence two major drivers of indirect reciprocity: a donor's propensity to trust and a receiver's reputation for giving. Either can be made higher or more reciprocating, giving rise to four mechanisms: contributing, discriminating, initiating and consolidating. In short, a boundary spanner plays an essential role in facilitating interorganisational trust. The existing literature has extensively studied the drivers of interorganisational trust, including prior interactions (Gulati, 1995; Gulati \& Sytch, 2008; Poppo et al., 2008), contracts (Malhotra \& Lumineau, 2011; Poppo \& Zenger, 2002), national culture (Dyer \& Chu, 2000; Sako \& Helper, 1998) and performance (Anderson \& Narus, 1990). I direct attention to another important class of variables: how the interorganisational relationship is designed. Because decision makers have direct control over such elements, they are of both theoretical interest and practical importance.

\section{Future research}

Because data are simulated, not from an empirical context, a simulation cannot be used to test a theory. Thus, an important next step is to find empirical contexts where implications of the simulation can be validated or invalidated. Such opportunities are plenty. The results are contingent on the general propensity to trust in the population. That is, population trust propensity has a strong direct effect on interorganisational trust, and the effect of indirect reciprocity depends strongly on population trust propensity. Correlates of propensity to trust at the micro level include personality (Colquitt et al., 2007; Kramer, 1999) and, in particular, agreeableness (Evans \& Revelle, 2008; Mooradian, Renzl, \& Matzler, 2006). At the macro level, we may expect the institutional environment to play a key role (Bachmann, 2011). For 
example, the legal context or formal certification of exchange partners will influence people's willingness to be vulnerable and their perceptions of others' trustworthiness (Bachmann \& Inkpen, 2011). Thus, the argument here is that indirect reciprocity occurs across a broad range of environments, but its strength and impact will vary. For instance, a growing literature, much of it based on responses to the World Value Survey (e.g. Porta, Lopez-De-Silane, Shleifer, \& Vishny, 1997), has documented international variations in perceptions of the extent to which others can be trusted. One is then naturally led to expect that, if boundary spanners are less useful under high propensities to trust, the usage of boundary spanners will vary across the world. In recent work along these lines, Bloom, Sadun, and Van Reenen (2012) find that the general level of trust in the population explains global variations in the centralisation of organisations (e.g. centralised decision power on hiring, capital expenditures, marketing and product innovation). The findings highlight that indirect reciprocity may lead to variation not only in the structure within but also between organisations.

The other main driver of reciprocity is a receiver's reputation, which in turn depends crucially on the availability of information. Direct observation through colocation is a natural driver. Thus, the results would suggest that trust is higher in co-located than distant relationships. Similarly, the results indicate that boundary spanners are more useful in offshoring than in non-offshoring relationships. More generally, direct observation is but one form of information transmission; other forms include verbal and written communication. For example, many companies today invest in creating online networks where employees can easily interact. Based on the results, one would expect interorganisational trust to be higher, and the usage of boundary spanners to be lower, the easier information spreads.

Moreover, opportunities exists to extend the theory. The models presented here are basic to reveal the underlying mechanisms. Numerous extensions are possible in future research. For example, I have modelled an interorganisational relationship as a series of interactions between organisations, but these relationships exist in many different forms. Variation exists on factors such as the number of organisations involved (two or more), the nature of the relationship (horizontal vs. vertical), and the presence of hierarchical structures (e.g. equity joint ventures). While the underlying mechanism uncovered here should be present in other interorganisational relationships as well, their manifestation may differ.

Coleman (1990) urges scientists to seek explanations for their phenomena of interest by analysing lower-level phenomena, which Wilson (1998) refers to as consilience. This call is highly relevant for researchers who study trust at the organisational level because, strictly speaking, organisations cannot trust - only their employees can. Ultimately, interorganisational trust comes from the individuals and their dispositions, actions and observations. In this paper I propose a bottom-up theory with indirect reciprocity as a causal mechanism to account for trust at the interpersonal level transforming into trust at the interorganisational level.

To use a consilience approach in future interorganisational trust research, one needs knowledge about (a) individual behaviour and (b) its aggregation to organisational behaviour. With respect to the first issue, I have focused on the indirect reciprocity that an individual may exhibit. With respect to the second, I have highlighted boundary spanners. Future research may well address other topics. For instance, in terms of individual behaviour, trust heuristics could be explored instead of indirect reciprocity (McEvily, 2011). As for aggregation, instead of the basic task structures 
analysed here, more interdependent tasks could be studied. Furthermore, the formal and informal structures (including their network properties) that pervade all organisations could be examined. All in all, this study represents just the beginning of a more thorough consilience approach to interorganisational trust.

\section{Acknowledgements}

I gratefully acknowledge the comments of Isabel Fernandez-Mateo, Javier Gimeno, Martin Kilduff, Phanish Puranam, Andrew Shipilov and Maciej Workiewicz, as well as those from the SOM reading group at UCL and seminar participants at Hong Kong University, INSEAD and Yale University. I also thank the editor and reviewers for insightful and constructive comments.

\section{Supplemental data}

The Online Appendix for this article can be accessed at doi:10.1080/21515581.2015.1108849

\section{Notes}

1. Part of this direct reciprocity may in fact be altruism, that is, unconditional kindness (Ashraf, Bohnet, \& Piankov, 2006; Cox, 2004; Dufwenberg, Gneezy, Güth, \& Van Damme, 2001). What matters here is less what drives this behavior than that the favor is returned by the receiver.

2. The focus is on pay back indirect reciprocity, where the donor gets rewarded (i.e. A helps B, and then C helps A). For pay forward indirect reciprocity, where A helps B, and then B helps C, see Pfeiffer, Rutte, Killingback, Taborsky, and Bonhoeffer (2005) and Rutte and Taborsky (2007).

3. This measure gives equal weight to each individual. I used alternative measures that put more weight on those who trust least (i.e. interorganisational trust is the level of trust of the 10th or 25 th percentile most trusting individual) or, oppositely, on those who trust most (i.e. interorganisational trust is the level of trust of the 75 th or 90 th percentile most trusting individual). The first set assumes that interorganisational trust can only be high if most people trust. The second set assumes that interorganisational trust will be high as long as at least a few people trust. The results are qualitatively similar to those presented here.

4. In the model without boundary spanner, the unconditional probability of observing is $n_{\mathrm{o}} / n$. For a boundary spanner it is $(1-p) q$. Equating the two gives $q=n_{\mathrm{o}} /[n(1-p)]$.

\section{Notes on contributor}

Bart S. Vanneste is an associate professor of strategy at the UCL School of Management at the University College London. He received his Ph.D. from the London Business School. He researches the governance of interorganizational relationships, with emphasis on relational contracts, formal contracts, and trust.

\section{References}

Aldrich, H. (1979). Organizations and environments. Englewood Cliffs, NJ: Prentice-Hall.

Aldrich, H., \& Herker, D. (1977). Boundary spanning roles and organization structure. Academy of Management Review, 2(2), 217-230.

Anderson, J. C., \& Narus, J. A. (1990). A model of distributor firm and manufacturer firm working partnerships. Journal of Marketing, 54(1), 42-58.

Ashraf, N., Bohnet, I., \& Piankov, N. (2006). Decomposing trust and trustworthiness. Experimental Economics, 9(3), 193-208.

Axelrod, R. (1984). The evolution of cooperation. New York: Basic Books. 
Axelrod, R. (1997). The complexity of cooperation: Agent-based models of competition and collaboration. Princeton, NJ: Princeton University Press.

Bachmann, R. (2011). At the crossroads: Future directions in trust research. Journal of Trust Research, 1(2), 203-213.

Bachmann, R., \& Inkpen, A. C. (2011). Understanding institutional-based trust building processes in inter-organizational relationships. Organization Studies, 32(2), 281-301.

Berg, J., Dickhaut, J., \& McCabe, K. (1995). Trust, reciprocity, and social history. Games and Economic Behavior, 10(1), 122-142.

Bhattacharya, R., Devinney, T. M., \& Pillutla, M. M. (1998). A formal model of trust based on outcomes. Academy of Management Review, 23(3), 459-472.

Bloom, N., Sadun, R., \& Van Reenen, J. (2012). The organization of firms across countries. Quarterly Journal of Economics, 127(4), 1663-1705.

Bradach, J. L., \& Eccles, R. G. (1989). Price, authority, and trust - From ideal types to plural forms. Annual Review of Sociology, 15, 97-118.

Bshary, R., \& Grutter, A. S. (2006). Image scoring and cooperation in a cleaner fish mutualism. Nature, 441(7096), 975-978.

Burt, R. S. (1992). Structural holes: The social structure of competition. Cambridge, MA: Harvard University Press.

Coleman, J. (1990). Foundations of social theory. Cambridge, MA: Harvard University Press.

Colquitt, J. A., Scott, B. A., \& LePine, J. A. (2007). Trust, trustworthiness, and trust propensity: A meta-analytic test of their unique relationships with risk taking and job performance. Journal of Applied Psychology, 92(4), 909-926.

Cook, K. S., \& Whitmeyer, J. M. (1992). Two approaches to social structure: Exchange theory and network analysis. Annual Review of Sociology, 18, 109-127.

Cox, J. C. (2004). How to identify trust and reciprocity. Games and Economic Behavior, 46(2), 260-281.

Currall, S. C., \& Inkpen, A. C. (2002). A multilevel approach to trust in joint ventures. Journal of International Business Studies, 33(3), 479-495.

Currall, S. C., \& Inkpen, A. C. (2006). On the complexity of organizational trust: A multi-level co-evolutionary perspective and guidelines for future research. In R. Bachmann \& A. Zaheer (Eds.), Handbook of trust research (pp. 235-246). Cheltenham: Edward Elgar.

Doney, P. M., \& Cannon, J. P. (1997). An examination of the nature of trust in buyer-seller relationships. Journal of Marketing, 2(2), 35-51.

Dufwenberg, M., Gneezy, U., Güth, W., \& Van Damme, E. (2001). Direct versus indirect reciprocity: An experiment. Homo Oeconomicus, 18(1), 19-30.

Dyer, J. H., \& Chu, W. (2000). The determinants of trust in supplier-automaker relationships in the U.S., Japan, and Korea. Journal of International Business Studies, 31(2), 259-285.

Dyer, J. H., \& Chu, W. (2003). The role of trustworthiness in reducing transaction costs and improving performance: Empirical evidence from the United States, Japan, and Korea. Organization Science, 14(1), 57-68.

Emerson, R. M. (1976). Social exchange theory. Annual Review of Sociology, 2, 335-362.

Engelmann, D., \& Fischbacher, U. (2009). Indirect reciprocity and strategic reputation building in an experimental helping game. Games and Economic Behavior, 67(2), 399-407.

Evans, A. M., \& Revelle, W. (2008). Survey and behavioral measurements of interpersonal trust. Journal of Research in Personality, 42(6), 1585-1593.

Fehr, E., \& Gächter, S. (2000). Fairness and retaliation: The economics of reciprocity. Journal of Economic Perspectives, 14(3), 159-181.

Fulmer, C. A., \& Gelfand, M. J. (2012). At what level (and in whom) we trust: Trust across multiple organizational levels. Journal of Management, 38(4), 1167-1230.

Gimeno, J., \& Woo, C. Y. (1996). Economic multiplexity: The stuctural embeddedness of cooperation in multiple relations of interdependence. Advances in Strategic Management, $13,323-362$.

Gouldner, A. W. (1960). The norm of reciprocity: A preliminary statement. American Sociological Review, 25(2), 161-178.

Granovetter, M. (1985). Economic action and social structure: The problem of embeddedness. American Journal of Sociology, 91(3), 481-510.

Greve, H. R., Baum, J. A. C., Mitsuhashi, H., \& Rowley, T. J. (2010). Built to last but falling apart: Cohesion, friction, and withdrawal from interfirm alliances. Academy of Management Journal, 53(2), 302-322. 
Gulati, R. (1995). Does familiarity breed trust? The implications of repeated ties for contractual choice in alliances. Academy of Management Journal, 38(1), 85-112.

Gulati, R., \& Nickerson, J. A. (2008). Interorganizational trust, governance choice, and exchange performance. Organization Science, 19(5), 688-708.

Gulati, R., \& Sytch, M. (2007). Dependence asymmetry and joint dependence in interorganizational relationships: Effects of embeddedness on a manufacturer's performance in procurement relationships. Administrative Science Quarterly, 52(1), 32-69.

Gulati, R., \& Sytch, M. (2008). Does familiarity breed trust? Revisiting the antecedents of trust. Managerial and Decision Economics, 29(2-3), 165-190.

Harrison, J. R., Carroll, G. R., \& Carley, K. M. (2007). Simulation modeling in organizational and management research. Academy of Management Review, 32(4), 1229-1245.

Kramer, R. M. (1999). Trust and distrust in organizations: Emerging perspectives, enduring questions. Annual Review of Psychology, 50(1), 569-598.

Kreps, D. M. (1990). A course in microeconomic theory. Princeton, NJ: Princeton University Press.

Krishnan, R., Martin, X., \& Noorderhaven, N. G. (2006). When does trust matter to alliance performance? Academy of Management Journal, 49(5), 894-917.

Lave, C. A., \& March, J. G. (1993). An introduction to models in the social sciences. Lanham, MD: University Press of America.

Leifer, R., \& Huber, G. P. (1977). Relations among perceived environmental uncertainty, organization structure, and boundary-spanning behavior. Administrative Science Quarterly, 22(2), 235-247.

Lewicki, R. J., \& Bunker, B. B. (1995). Trust in relationships: A model of development and decline. In B. B. Bunker \& J. Z. Rubin (Eds.), Conflict, cooperation, and justice: Essays inspired by the work of Morton Deutsch (pp. 133-173). San Francisco, CA: Jossey-Bass.

Luo, Y. (2001). Antecedents and consequences of personal attachment in cross-cultural cooperative ventures. Administrative Science Quarterly, 46(2), 177-201.

Malhotra, D., \& Lumineau, F. (2011). Trust and collaboration in the aftermath of conflict: The effects of contract structure. Academy of Management Journal, 54(5), 981-998.

March, J., \& Simon, H. (1958). Organizations. New York: Wiley.

Mayer, R. C., Davis, J. H., \& Schoorman, F. D. (1995). An integrative model of organizational trust. Academy of Management Review, 20(3), 709-734.

McEvily, B. (2011). Reorganizing the boundaries of trust: From discrete alternatives to hybrid forms. Organization Science, 22(5), 1266-1276.

Milinski, M., Semmann, D., Bakker, T. C. M., \& Krambeck, H. J. (2001). Cooperation through indirect reciprocity: image scoring or standing strategy? Proceedings of the Royal Society of London, 268(1484), 2495-2501.

Moldoveanu, M. C., \& Baum, J. A. C. (2011). "I think you think I think you're lying": The interactive epistemology of trust in social networks. Management Science, 57(2), 393-412.

Molm, L. D., Collett, J. L., \& Schaefer, D. R. (2007). Building solidarity through generalized exchange: A theory of reciprocity. American Journal of Sociology, 113(1), 205-242.

Mooradian, T., Renzl, B., \& Matzler, K. (2006). Who Trusts? Personality, Trust and Knowledge Sharing. Management Learning, 37(4), 523-540.

Nielsen, B. B. (2011). Trust in strategic alliances: Toward a co-evolutionary research model. Journal of Trust Research, 1(2), 159-176.

Nowak, M. A., \& Sigmund, K. (1998). Evolution of indirect reciprocity by image scoring. Nature, 393(6685), 573-577.

Nowak, M. A., \& Sigmund, K. (2005). Evolution of indirect reciprocity. Nature, 437(7063), 1291-1298.

Ortmann, A., Fitzgerald, J., \& Boeing, C. (2000). Trust, reciprocity, and social history: A reexamination. Experimental Economics, 3(1), 81-100.

Perrone, V., Zaheer, A., \& McEvily, B. (2003). Free to be trusted? Organizational constraints on trust in boundary spanners. Organization Science, 14(4), 422-439.

Pfeiffer, T., Rutte, C., Killingback, T., Taborsky, M., \& Bonhoeffer, S. (2005). Evolution of cooperation by generalized reciprocity. Proceedings of the Royal Society: Biological Sciences, 272(1568), 1115-1120.

Pillutla, M. M., Malhotra, D., \& Murnighan, J. K. (2003). Attributions of trust and the calculus of reciprocity. Journal of Experimental Social Psychology, 39(5), 448-455. 
Poppo, L., \& Zenger, T. (2002). Do formal contracts and relational governance function as substitutes or complements? Strategic Management Journal, 23(8), 707-725.

Poppo, L., Zhou, K. Z., \& Ryu, S. (2008). Alternative origins to interorganizational trust: An interdependence perspective on the shadow of the past and the shadow of the future. Organization Science, 19(1), 39-55.

Porta, R. L., Lopez-De-Silane, F., Shleifer, A., \& Vishny, R. W. (1997). Trust in large organizations. American Economic Review Papers and Proceedings, 87(2), 333-338.

Puranam, P., Alexy, O., \& Reitzig, M. G. (2014). What's "new" about new forms of organizing? Academy of Management Review, 39(2), 162-180.

Puranam, P., \& Vanneste, B. S. (2009). Trust and governance: Untangling a tangled web. Academy of Management Review, 34(1), 11-31.

Reeves-Ellington, R. (2004). Trustscapes and distrustscapes: A multi-level approach for understanding stability and change. Multi-Level Issues in Organizational Behavior and Processes, 3 , 91-148.

Ring, P. S., \& Van de Ven, A. H. (1992). Structuring cooperative relationships between organizations. Strategic Management Journal, 13(7), 483-498.

Rousseau, D. M. (1985). Issues of level in organizational research: Multi-level and cross-level perspectives. Research in Organizational Behavior, 7, 1-37.

Rousseau, D. M. (2004). Now let's make multi-level research on trust doable. Multi-Level Issues in Organizational Behavior and Processes, 3, 159-166.

Rousseau, D. M., Sitkin, S. B., Burt, R. S., \& Camerer, C. (1998). Not so different after all: A cross-discipline view of trust. Academy of Management Review, 23(3), 393-404.

Rutte, C., \& Taborsky, M. (2007). Generalized reciprocity in rats. PLoS Biology, 5(7), 1421-1425.

Sako, M., \& Helper, S. (1998). Determinants of trust in supplier relations: Evidence from the automotive industry in Japan and the United States. Journal of Economic Behavior \& Organization, 34(3), 387-417.

Schilke, O., \& Cook, K. S. (2013). A cross-level process theory of trust development in interorganizational relationships. Strategic Organization, 11(3), 281-303.

Scott, W. R. (1998). Organizations: Natural, rational and open systems. Englewood Cliffs, NJ: Prentice-Hall.

Seabright, M. A., Levinthal, D. A., \& Fichman, M. (1992). Role of individual attachments in the dissolution of interorganizational relationships. Academy of Management Journal, 35(1), 122-160.

Seinen, I., \& Schram, A. (2006). Social status and group norms: Indirect reciprocity in a repeated helping experiment. European Economic Review, 50(3), 581-602.

Serva, M. A., Fuller, M. A., \& Mayer, R. C. (2005). The reciprocal nature of trust: A longitudinal study of interacting teams. Journal of Organizational Behavior, 26(6), 625-648.

Shapiro, D. L., Sheppard, B. H., \& Cheraskin, L. (1992). Business on a handshake. Negotiation Journal, 8(4), 365-377.

Shipilov, A. V., \& Li, S. X. (2012). The missing link: The effect of customers on the formation of relationships among producers in the multiplex triads. Organization Science, 23(2), 472-491.

Stanca, L. (2009). Measuring indirect reciprocity: Whose back do we scratch? Journal of Economic Psychology, 30(2), 190-202.

Stinchcombe, A. L. (1965). Social structure and organizations. In J. G. March (Ed.), Handbook of organizations (pp. 142-193). Chicago, IL: Rand McNally.

Thompson, J. D. (1967). Organizations in action. New York, NY: McGraw-Hill.

Tushman, M. L., \& Scanlan, T. J. (1981). Boundary spanning individuals: Their role in information transfer and their antecedents. Academy of Management Journal, 24(2), 289-305.

Uzzi, B. (1997). Social structure and competition in interfirm networks: The paradox of embeddedness. Administrative Science Quarterly, 42(1), 37-69.

Van de Ven, A. H. (1976). On the nature, formation, and maintenance of relations among organizations. Academy of Management Review, 1(4), 24-36.

Vanneste, B. S., Puranam, P., \& Kretschmer, T. (2014). Trust over time in exchange relationships: Meta-analysis and theory. Strategic Management Journal, 35(12), 1891-1902.

Wedekind, C., \& Milinski, M. (2000). Cooperation through image scoring in humans. Science, 288(5467), 850-852.

Wilson, E. O. (1998). Consilience: The unity of knowledge. New York: Knopf.

Zaheer, A., McEvily, B., \& Perrone, V. (1998). Does trust matter? Exploring the effects of interorganizational and interpersonal trust on performance. Organization Science, 9(2), 141-159. 


\section{Appendix}

The number of observations made is a proxy for the information that a donor has available. This appendix shows that (a) if fewer observers are present, the number of interactions the average donor will have observed declines, and (b) this decline in number of observations for the average donor is less with a boundary spanner. The first is straightforward: if the chance of seeing decreases, less will be seen. The second is derived below. It follows that a boundary spanner is more effective at consolidating information with fewer observers.

Because the probabilities of interacting and observing are independent across interactions (within a period), it is sufficient to look at these probabilities for a given interaction to investigate the impact of a boundary spanner. Without a boundary spanner, the average donor observed the last interaction on the receiving side with probability obs $/ n$. With a boundary spanner, this probability is the weighted average when the donor is the boundary spanner and when it is someone else: $(1-p)[p q+($ obs $-(1-p) q) /(n-1)]$ (see Table A1). As anticipated, with or without a boundary spanner, the average donor will have seen fewer interactions with fewer observers (because the probabilities are increasing in the number of observers). One observer less reduces the probability for the average donor with $1 / n$ without boundary spanner and $(1-p) /(n-1)$ with boundary spanner. The reduction is less with a boundary spanner as long as $p>1 / n$, which is always the case per the definition of a boundary spanner (i.e. a boundary spanner is more likely to interact). Hence, information becomes more consolidated with a boundary spanner relative to without a boundary spanner as the number of observers goes down.

Table A1. Probabilities for an interaction.

\begin{tabular}{|c|c|c|c|}
\hline & \multirow[t]{2}{*}{ Without boundary spanner } & \multicolumn{2}{|c|}{ With boundary spanner } \\
\hline & & Boundary spanner & Others \\
\hline Donor & 1 & $p$ & $1-p$ \\
\hline (if on giving side) & $\bar{n}$ & & $\overline{n-1}$ \\
\hline Observer & obs & $(1-p) q$ & obs $-(1-p) q$ \\
\hline (if on receiving side) & $\bar{n}$ & & $n-1$ \\
\hline Observe for average donor & $\frac{\mathrm{obs}}{n}$ & $(1-p)\left[p q+\frac{\text { obs }-(}{n-}\right.$ & $\left.\frac{-p) q}{1}\right]$ \\
\hline
\end{tabular}

